\title{
A QUANTITATIVE SYSTEM FOR STAGING AVASCULAR NECROSIS
}

MARVIN E. STEINBERG. GERALD D. HAYKEN, DAVID R. STEINBERG

From the University of Pennsylvania, Philadelphia, USA

Much of the current confusion and contradiction on the treatment of avascular necrosis of the femoral head is caused by the lack of an agreed efficient, quantitative system for evaluation and staging.

We have used a new system to evaluate over 1000 hips with avascular necrosis during a period of 12 years; it has proved to be very valuable.

The system is based on the sequence of pathological events known to take place. It allows accurate quantification in both early and later stages, does not use older, invasive diagnostic procedures, and incorporates the newer techniques of bone scanning and MRI. Clinical records of pain and reduced function are not a specific part of the system, although they help to determine treatment and outcome.

Hips are first placed into one of seven stages from 0 to VI, based upon the type of radiological change. The extent of involvement is then measured. This allows more accurate evaluation of progression or resolution and better comparison of different methods of management. The system also helps to provide a prognosis and to decide on the best available method of treatment.

J Bone Joint Surg [Br] 1995:77-B:34-41.

Received 7 January 1994: Accepted after revision 24 June 1994

M. E. Steinberg. MD. Professor and Vice-Chairman

Department of Orthopaedic Surgery. University of Pennsylvania School of Medicine, 3400 Spruce Street. Philadelphia. Pennsylvania 19104. USA.

G. D. Hayken. MD. Chief. Department of Orthopaedic Surgery Memorial Hospital of Burlington County. Mt Holly. New Jersey 08060. USA.

D. R. Steinberg. MD. Assistant Professor

Department of Orthopaedic Surgery. University of California. 2230 Stockton Boulevard. Sacramento. California 95817. USA.

Correspondence should be sent to Professor M. E. Steinberg.

(1)1995 British Editorial Society of Bone and Joint Surgery

$0301-620 \mathrm{X} / 95 / 1926 \$ 2.00$
There is some confusion and uncertainty about both the natural history and the results of treatment of avascular necrosis of the femoral head (AVN). This is because different methods of staging are used, and most of these do not quantify the extent of involvement of the femoral head and acetabulum. Many of the systems do not make use of current methods of diagnosis and evaluation, but include older techniques which are no longer used. In addition, the inclusion of symptoms and physical findings as part of the evaluation is often misleading.

The system which we describe is similar to that outlined by Marcus, Enneking and Massam (1973). Ficat and Arlet (1980) and Ficat (1985). We have used it since 1979, with only slight modifications, to stage over 1000 hips affected with AVN (Steinberg. Hayken and Steinberg 1984), and also to evaluate lesions in the shoulder.

The most important feature of our system is that in addition to defining stages, it also quantifies the extent of involvement of the femoral head. It uses the latest technological advances in technetium bone scanning and quantitative MRI, and does not require invasive methods such as intraosseous pressure measurements and venography (Hungerford 1979: Steinberg 1988: Steinberg et al 1990). The patients ${ }^{\circ}$ symptoms and physical findings are carefully recorded since they help to determine progress and treatment, but they are not part of the staging system itself. This is important because there is often little correlation between the stage or extent of femoral head involvement and the symptoms or physical findings.

It is clear that a uniform method of evaluating and staging AVN is needed to allow direct comparison between series. Much of the current ambiguity and confusion would be eliminated by its use, and this could improve management of the condition.

\section{PATIENTS AND METHODS}

We have used the new method to evaluate over 1000 hips affected with AVN, employing good-quality anteroposterior (AP) and lateral radiographs, and, for preradiographic stages, technetium bone scans and MRI. We have also used the Harris rating system for separate clinical evaluation.

Seven stages of involvement are identified (Table I). After staging. the extent of involvement of the femoral head and acetabulum is measured or estimated and recorded as mild (A), moderate (B), or severe (C) (Table II). For 
Table I. Criteria for staging AVN

\begin{tabular}{ll}
\hline Stage & \\
\hline 0 & Normal or non-diagnostic radiograph, bone scan and MRI \\
I* & Normal radiograph. abnormal bone scan and/or MRI \\
II* & Abnormal radiograph showing 'cystic' and sclerotic changes in the femoral head \\
III* & Subchondral collapse producing a crescent sign \\
IV* & Flattening of the femoral head \\
V* & Joint narrowing with or without acetabular involvement \\
VI & Advanced degenerative changes \\
\hline * the extent or grade of involvement should also be indicated as A, mild: B, moderate; or C, \\
severe (see text and Table II)
\end{tabular}

routine clinical use, estimation is quick and easy; for research projects and publications extent should be measured and expressed in percentages or millimetres, as described later. Neither part of the system is arbitrary, and both stage and extent correlate closely with the sequence of pathological events which takes place in AVN.

\section{Staging}

Stage 0 . Stage 0 is suspicion of AVN although the diagnosis cannot be confirmed. Plain radiographs are normal; MRI and bone scans are either normal or non-diagnostic (Figs 1 and 2).

There is a definite lag between the vascular insult and the appearance of imaging abnormalities. When vascular compromise is incomplete and the involved area is small, this may escape detection by current imaging methods, but as new and more sensitive methods are developed, earlier diagnosis will be possible, smaller lesions will be detected, and the diagnosis as stage 0 may be confirmed. This stage allows for technological advances in diagnosis and will extend the useful life of the staging system.

At present, we include in stage 0 patients with known risk factors and abnormal but not diagnostic MRI or bone scans, and also patients with hip pain but normal imaging. AVN is often already present in the opposite hip, and careful review and repeated imaging are necessary. Later changes may confirm the diagnosis, but no changes, or reversion to normal, may make it impossible at present to determine whether the patient had minimal AVN with spontaneous resolution, or some other condition. Biopsy or other invasive methods is rarely justified, and would often be negative or equivocal at this stage.

Stage $I$. In this stage plain radiographs are within normal limits, but either the MRI or the technetium scan or both indicates AVN. These methods can show injury and death of marrow and bone cells with resultant changes in and around the area of involvement, before they are visible radiologically (Mitchell et al 1986, 1987, 1989) (Figs 3, 4 and 5).

Stage II. Radiographs show definite changes consistent with AVN, such as alternating areas of radiolucency and sclerosis, at times demarcated from normal bone by a sclerotic border (Figs 6 and 7). This demarcation signifies repair; the sclerotic appearance is due to new, living bone laid down on old, dead trabecula. Areas of radiolucency represent bone resorption; they are often filled with fibrous or granulation tissue, amorphous debris, and even cartilage. Other authors have reported generalised osteopenia as an early finding in AVN, but we have seen this only rarely.

Stage III. This is defined by the appearance of a radiolucent crescent sign just beneath the subchondral end plate of the femoral head, indicating collapse of cancellous trabecula without flattening of the articular surface (Figs 8 and 9). The crescent sign does not always develop during progressive involvement and may often be visible only on the anteroposterior or the lateral film. Only a small percentage of hips fit the criteria for stage III, but we consider that this should not be combined with the more advanced finding of flattening of the femoral head. In stage III, the femoral head remains spherical, and it is therefore theoretically possible to preserve its shape by bone grafting or other procedures.

Stage IV. In this stage there is definite flattening of the articular surface, seen on either the AP or the lateral radiograph. The collapse is usually in the anterolateral or superior weight-bearing segments of the femoral head (Figs 10 and 11). Small amounts of collapse may not show up on plain radiographs, but may be detected by either laminograms or CT. We rarely use these methods, but they should be considered when plain films show no evidence of collapse and the patient experiences more than the anticipated amount of pain and disability. The acetabulum appears radiologically normal at this stage, but observations at operations confirm that there is often some degeneration in the acetabular articular cartilage (Steinberg, Corces and Fallon 1989).

Stage IV has serious prognostic and therapeutic implications because the changes are irreversible. Prophylactic treatment may be indicated in early stage-IV lesions with no significant pain or disability, but the results are often disappointing, and many of these patients will need only symptomatic treatment until arthroplasty is indicated.

Stage $V$. In this stage there is clear radiological evidence of 


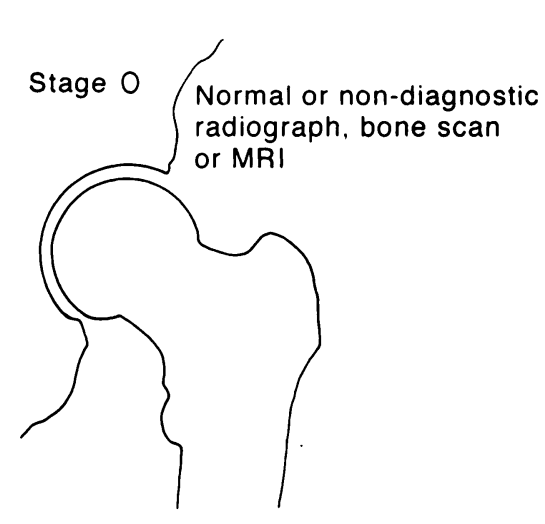

Fig. 1

Figure 1 - Stage 0. Figure 2a - Radiograph of the hips of a renal transplant patient with bilateral thigh and knee pain is within normal limits. except for a suggestion of a small sclerotic area in the left femoral head. Figure $2 b-M R I$ shows a minor decrease in signal intensity in both femoral heads. interpreted as within normal limits.

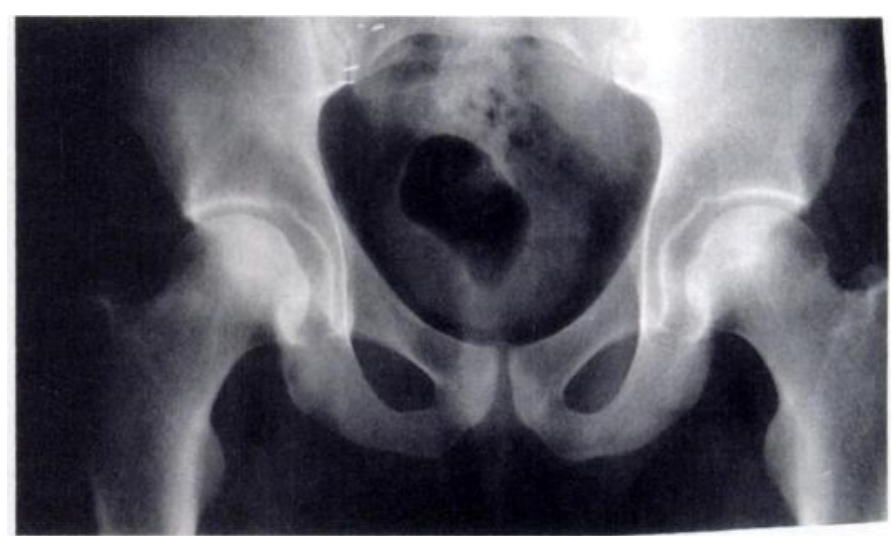

Fig. 2a

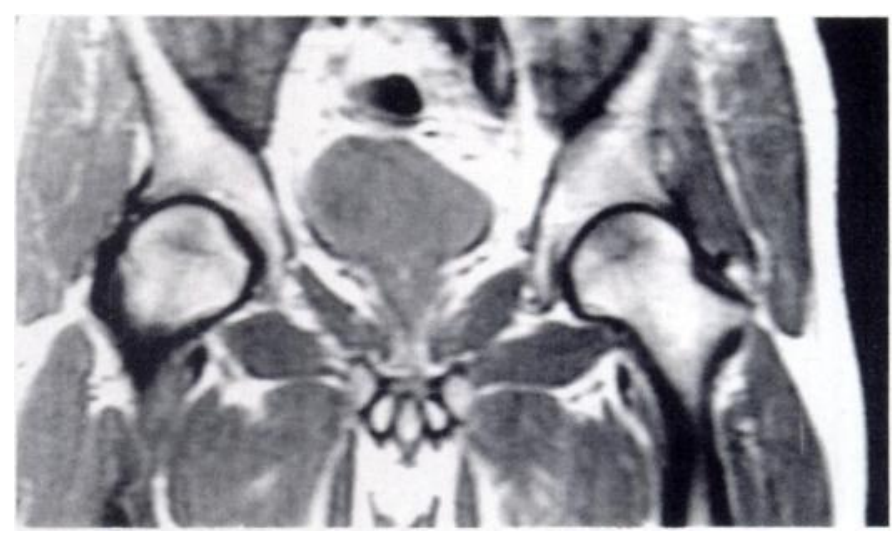

Fig. $2 b$

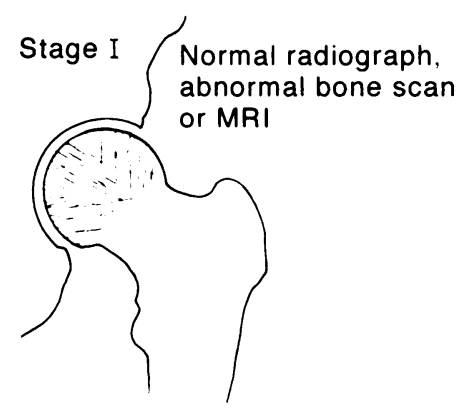

Fig. 3

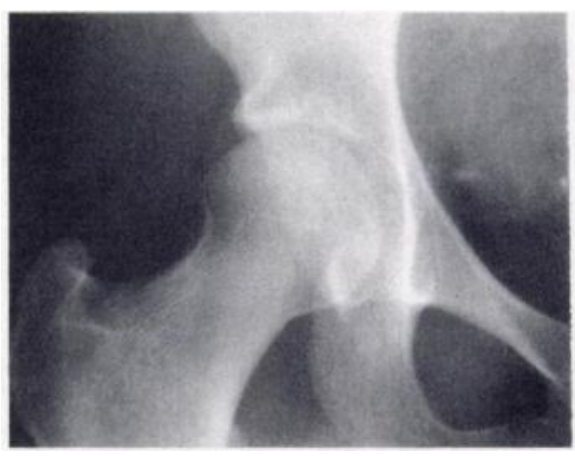

Fig. $4 \mathrm{a}$

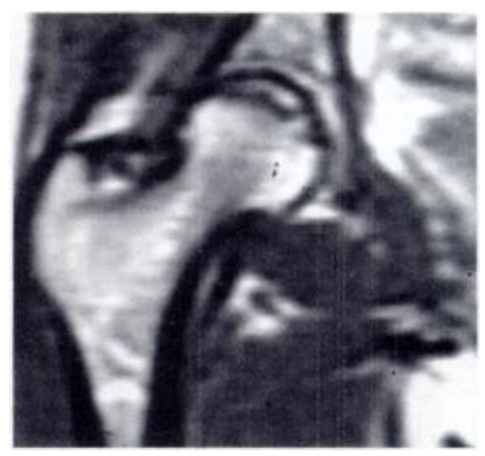

Fig. th

Figure 3 - Stage I. Figure 4a - Radiograph of a young patient who developed right hip pain after renal transplantation. Figure 4 b - MRI shows a decreased signal intensity in the femoral head. characteristic of avascular necrosis. The bone scan was normal.

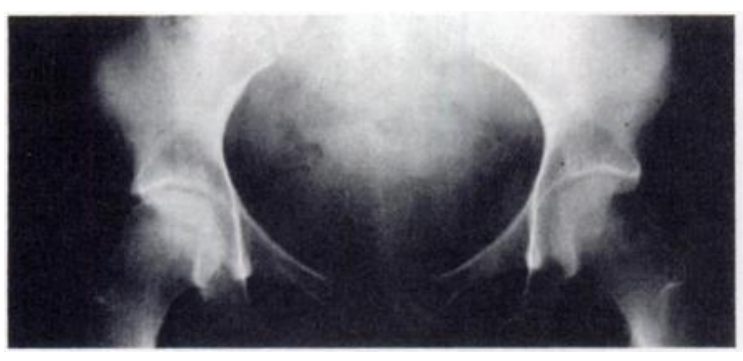

Fig. 5a

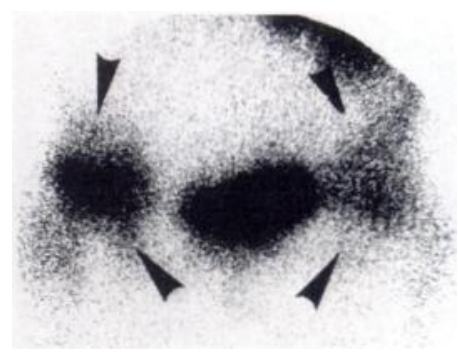

Fig. $5 b$

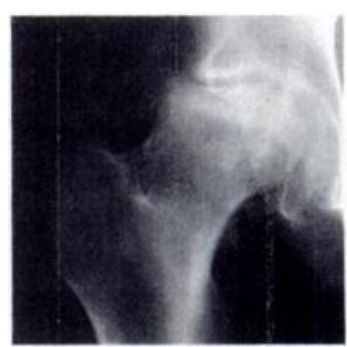

Fig. 5c

Findings in a patient with stage-I involvement of the right hip. Figure $5 \mathrm{a}-$ The initial radiograph is normal. Figure $5 \mathrm{~b}-\mathrm{A}$ bone scan shows increased uptake in the right femoral head, giving the diagnosis of avascular necrosis. Figure $5 \mathrm{c}-$ Film taken three months later shows collapse of the femoral head. 


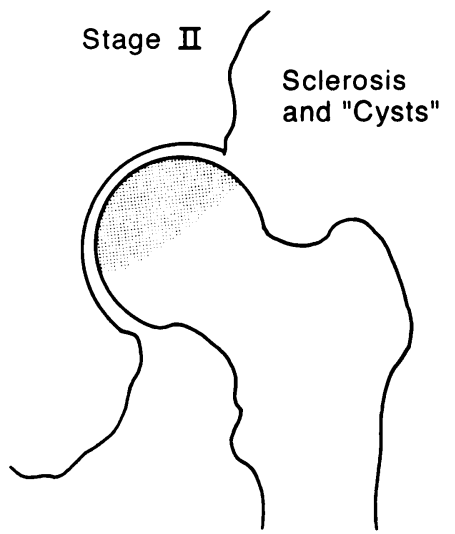

Fig. 6

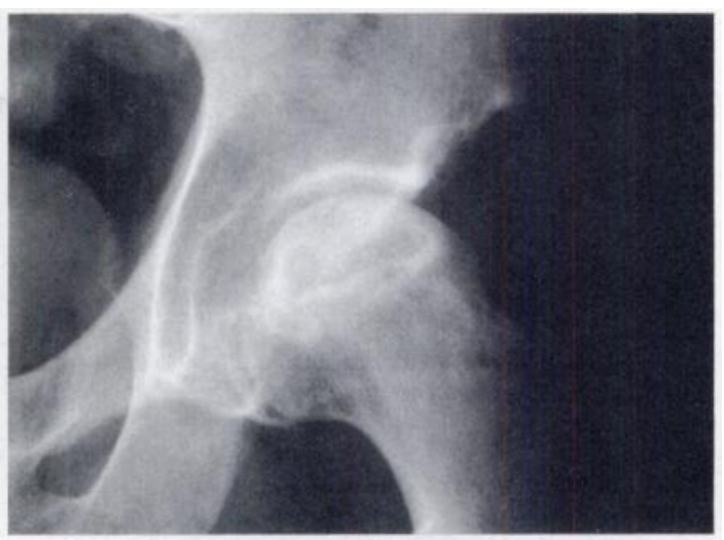

Fig. 7

Stage II. The areas of sclerosis and lucency within the femoral head are characteristic of avascular necrosis.

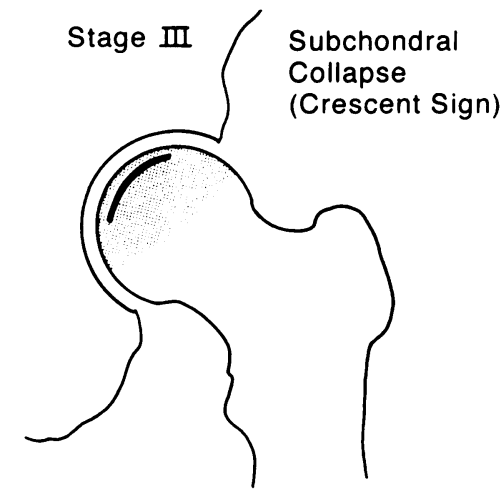

Fig. 8

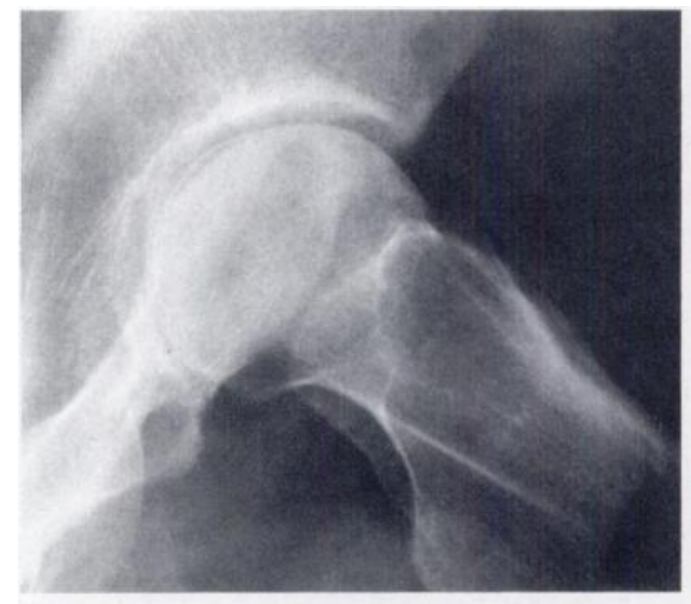

Fig. 9

Stage III. Subchondral collapse is indicated by the appearance of a crescent sign without flattening of the femoral head. The lateral radiograph shows a typical crescent sign.

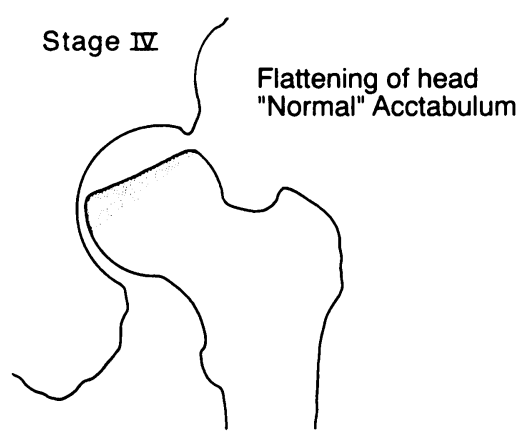

Fig. 10

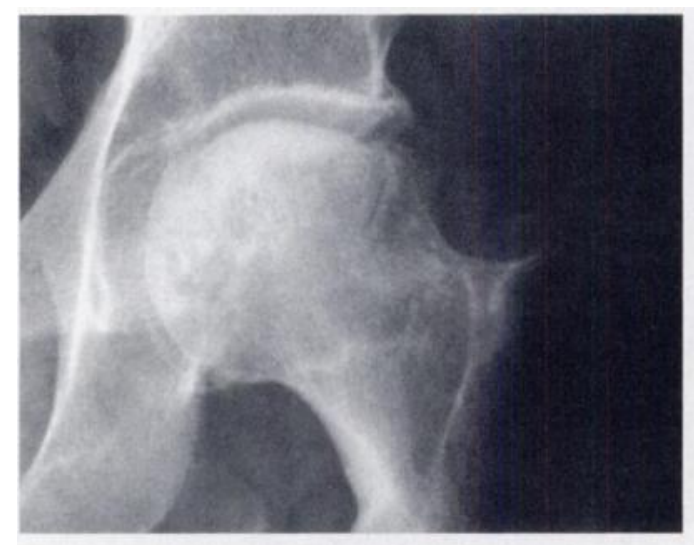

Fig. 11

Stage IV. There is flattening of the femoral head due to collapse of the superior weight-bearing region. without radiological evidence of acetabular involvement. 


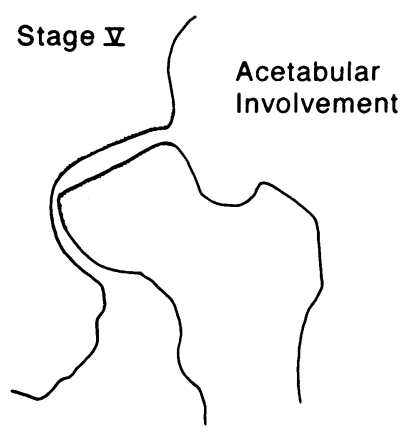

Fig. 12

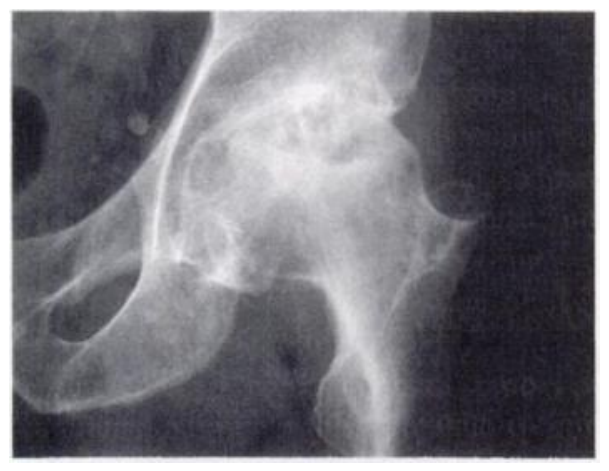

Fig. 13a

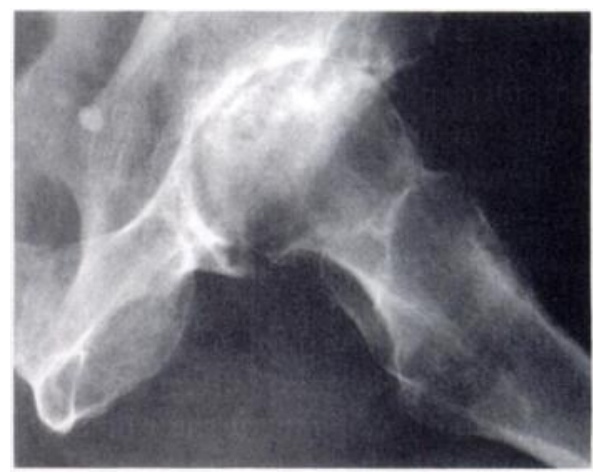

Fig. 1.3b

Stage V. There is acetabular involvement in addition to flattening of the femoral head, best seen in the lateral projection. Secondary changes in the acetabulum include joint-line narrowing, sclerosis, and cyst formation.

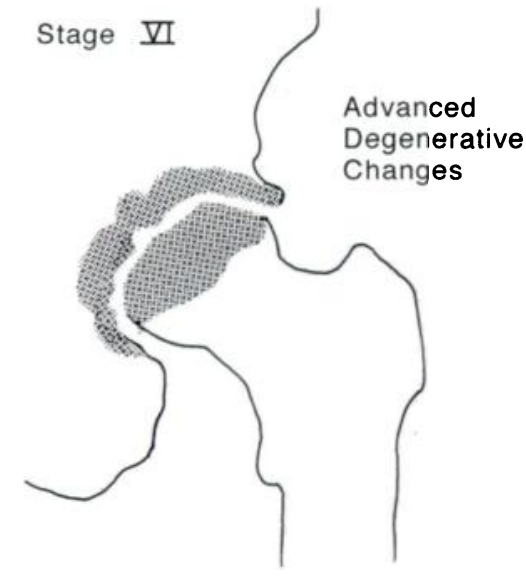

Fig. 14

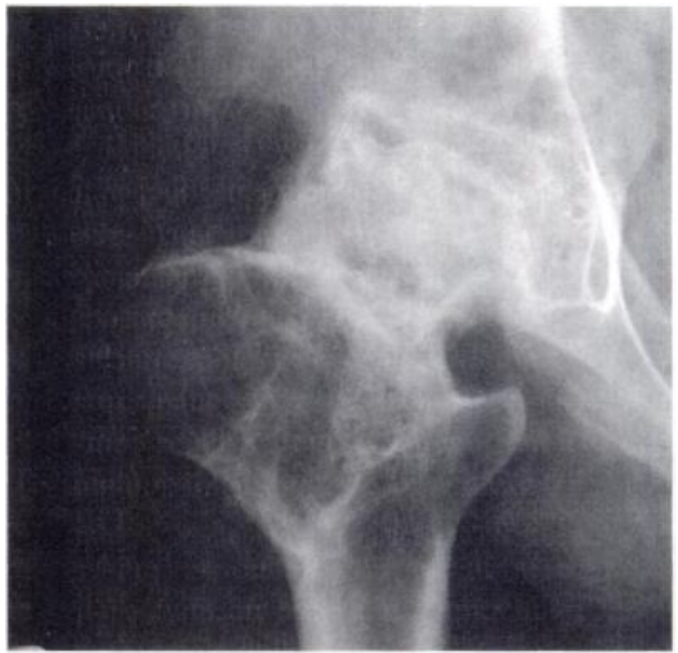

Fig. 15

Stage VI. There are advanced degenerative changes involving the femoral head and the acetabulum. An intertrochanteric osteotomy had been performed previously.

acetabular involvement. In our experience this almost always follows flattening of the femoral head and is a secondary degenerative process, not due to primary avascularity of pelvic bone. The earliest change is joint-line narrowing, due to degenerative changes of the articular cartilage of the acetabulum. Later, there are areas of 'cyst' formation and sclerosis above the acetabulum with small marginal osteophytes (Figs 12 and 13).

This transition from stage IV to stage $V$ has some therapeutic importance, since replacement of the femoral head may be considered in stage IV, but total hip replacement is required once there is definite acetabular involvement.

Stage VI. This describes advanced degenerative changes with virtually complete obliteration of the joint line. Other systems have combined our stages V and VI, but we have seen a small number of patients with changes that can clearly be distinguished from stage $\mathrm{V}$ and deserve a separate staging (Figs 14 and 15 ).

Extent of involvement. After the type of change has determined the stage of AVN, the extent of involvement is estimated or measured. For routine clinical purposes this can be determined visually as mild (A), moderate (B), or severe $(\mathrm{C})$. More precise measurement for research purposes records the calculated percentage of head involvement and the collapse in millimetres; these figures are then used to place the hip into the three categories A, B, or C (Table II). No attempt is made to quantify the extent of involvement in stages 0 or VI.

Stage $I$. In stage I the percentage of abnormal femoral head on the MRI can be calculated by a computerised program, such as ANALYZE, or an approximation can be made from estimating the average area of abnormality seen on serial MRI cuts. Such quantification cannot be done from a bone scan.

Stage II. In stage II the abnormal area of the femoral head is measured on both AP and frog-lateral views by tracing outlines of the whole head and the involved segment on to tracing paper and using either a manual point-counting technique (Fig. 16) or quantitative digital image analysis, by such methods as the MOP-3 Interactive Digitizer (Carl Zeiss, Oberkochen. Germany). The percentage involvement 


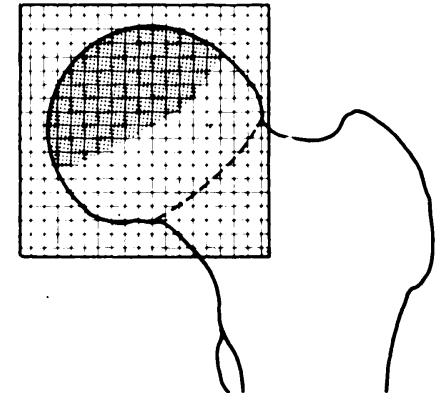

Fig. 16

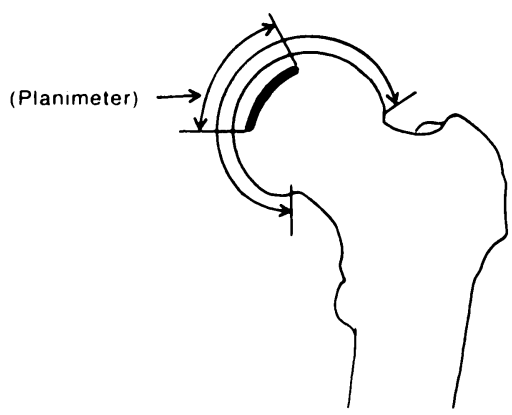

Fig. 17

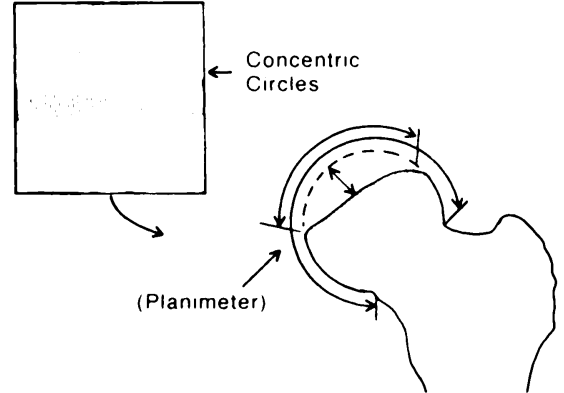

Fig. 18

Figure 16 - Diagram showing the method of determining the percentage of involvement of the femoral head by point-counting with a grid. Figure 17 - Method of quantifying the extent of subchondral collapse by measuring the lengths of the crescent and of the entire articular surface. Figure 18 - Method of measuring the extent and degree of flattening of the femoral head in stage IV. The normal contour is established by the use of concentric circles. The percentage of the surface involved is determined by measuring with a planimeter. The extent of the collapse is measured in millimetres.

Table II. Quantification of the extent of involvement hy AVN

\begin{tabular}{|c|c|c|}
\hline Stage & Grade & \\
\hline I and II & $\begin{array}{l}\text { A, mild } \\
\text { B, moderate } \\
\text { C. severe }\end{array}$ & $\begin{array}{l}<15 \% \text { of head involvement as seen on radiograph or MRI } \\
15 \% \text { to } 30 \% \\
>30 \%\end{array}$ \\
\hline III & $\begin{array}{l}\text { A, mild } \\
\text { B, moderate } \\
\text { C. severe }\end{array}$ & $\begin{array}{l}\text { subchondral collapse (crescent) beneath }<15 \% \text { of articular surface } \\
\text { crescent beneath } 15 \% \text { to } 30 \% \\
\text { crescent beneath }>30 \%\end{array}$ \\
\hline IV & $\begin{array}{l}\text { A. mild } \\
\text { B. moderate } \\
\text { C. severe }\end{array}$ & $\begin{array}{l}<15 \% \text { of surface has collapsed and depression is }<2 \mathrm{~mm} \\
15 \% \text { to } 30 \% \text { collapsed or } 2 \text { to } 4 \mathrm{~mm} \text { depression } \\
>30 \% \text { collapsed or }>4 \mathrm{~mm} \text { depression }\end{array}$ \\
\hline V & A. $B$ or $C$ & $\begin{array}{l}\text { average of femoral head involvement, as determined in stage IV, } \\
\text { and estimated acetabular involvement }\end{array}$ \\
\hline
\end{tabular}

on the AP and lateral views is then multiplied to determine the total volume affected. This is not mathematically precise, but is sufficiently accurate to be useful. Quantitative CT, if available, can also be used.

Stage III. In stage III it is first necessary to decide whether the crescent sign is more prominent on the AP or lateral view. This view is then used to measure the length of the crescent, and express it as a percentage of the length of the entire articular surface (Fig. 17), using either a map-reading planimeter or specially designed grids (Sugioka, Katsuki and Hotokebuchi 1982).

Stage IV. Measurement is made on either the AP or the lateral film. whichever shows the greatest collapse. The outline of the femoral head is transferred on to tracing paper, and the normal contour before collapse is reconstituted using concentric circles. The length of the collapsed segment is then measured and expressed as a percentage of the entire articular surface, while the maximum depression of the collapsed segment is measured and expressed in millimetres (Fig. 18). This can also be done using special grids (Sugioka et al 1982).

Stage $V$. In stage $V$ the extent and amount of collapse of the femoral head are measured as described for stage IV, and the degree of acetabulum involved is estimated. The average of femoral and acetabular involvement then determines the grade assigned. For intermediate results the extent of head involvement is the deciding factor. For example, femoral head involvement of grade $\mathrm{C}$ with acetabular involvement of grade B is recorded as a grade C hip.

\section{RELIABILITY OF STAGING AND GRADING}

We evaluated our system for reproducibility of measurement, and for the identification and measurement of changes in comparison with other non-quantitative methods of staging. An essential feature of our system is the measurement of the size of lesions in the early stages. We reviewed MRI studies of ten stage-I hips with from $2.8 \%$ to $52.3 \%$ involvement on a SUN work station using an imageanalysis software package (ANALYZE) to calculate the relative volume of the necrotic lesion as a percentage of the entire femoral head. The ten hips were evaluated by three independent observers who each made three sets of measurements on each case, providing 90) separate determinations. The resultant data were analysed by a biostatistician.

There was relatively little variation in repeated measurements made by the same observer, but more variability between observers. For this, the reliability coefficient for femoral head measurement was $89.5 \%$, for lesion measurement $87.0 \%$, and for the ratio of lesion to the whole head $81.9 \%$. These correlations are high for measurements of 


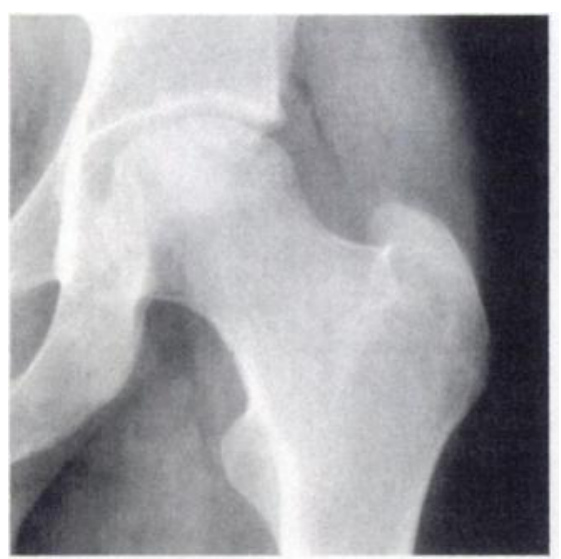

Fig. 19a

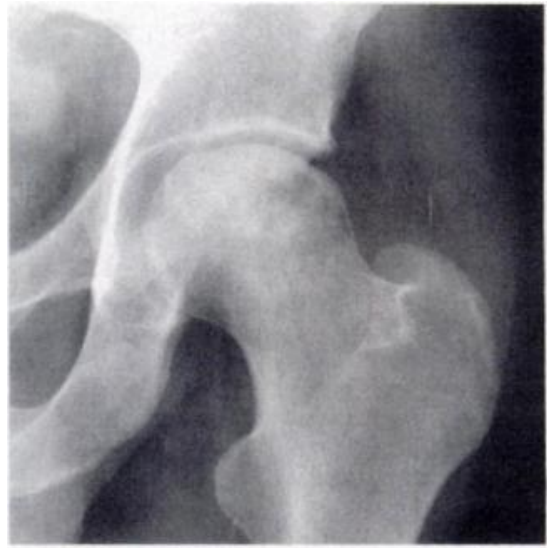

Fig. 19b

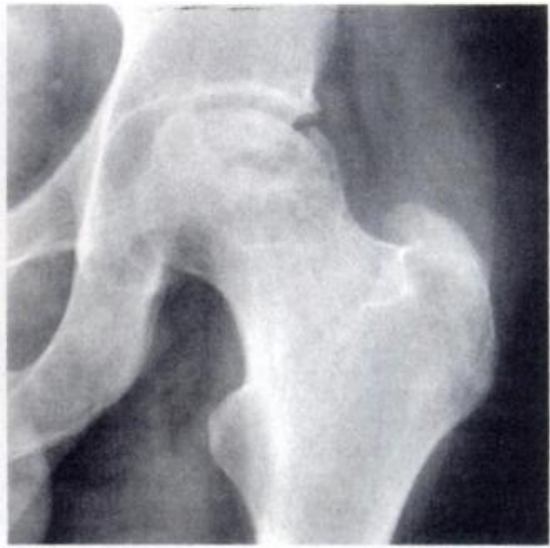

Fig. 19c

Radiographs of a patient with a stage-IV lesion. In one month this progressed from stage IV-A (a) to stage IV-B (b) and in another three months to stage IV-C (c). The progression is clearly identified by the quantitative method of staging and grading.

this type and indicate that our method of evaluation is reliable enough to be clinically useful.

We then compared calculations of lesion size made by MRI with those made from plain radiographs for 14 stageII hips. For small lesions on $\mathrm{MRI}(<15 \%$; grade $\mathrm{A})$ radiographs showed a mean volume $8 \%$ larger than that on MRI. For large lesions (> 30\%; grade $\mathrm{C}$ ) radiographs showed a mean volume $5.7 \%$ smaller. Considering that MRI and radiography record different biophysical phenomena and use different techniques to calculate size, these measurements were surprisingly close. Variability was, of course, greater when size was simply estimated rather than measured.

We then compared the reliability of the system with that of the non-quantitative staging described by Ficat and Arlet (1980) and Ficat (1985), which is the method most widely used. Our staging and grading were generally more reliable because there was less ambiguity in distinguishing between stages, and the subjective evidence of patients ${ }^{\circ}$ symptoms was eliminated. Most importantly, our method recorded progression of lesions in extent of involvement which was missed when sizes were not measured; by the older method progression was only indicated when it was great enough to cause a change from one stage to the next (Fig. 19).

We confirmed this by evaluating 115 hips with AVN independently on both our system and the Ficat system. We found radiographic progression by measurement in $74 \%$ but this could be identified in only $50 \%$ using the Ficat method. For 45 hips in stage IV, with collapse of the femoral head, our method showed deterioration in $66 \%$, while the Ficat system indicated progression in only $15 \%$.

We also studied 73 hips with early AVN in stages I and II, to evaluate the effect of lesion size on outcome after core decompression and bone grafting (Steinberg et al 1992) and the results are shown in Table III. These confirm a clear correlation between lesion size and outcome as measured by radiological progression, clinical improvement, and the need for hip replacement, but there were no significant differences between stages I and II. This indi- cates that before collapse of the femoral head, lesion size rather than stage may be the most important determinant of clinical outcome.

\section{DISCUSSION}

There is growing recognition that the size of the necrotic segment as well as the stage is important in both prognosis and treatment (Bonfiglio and Bardenstein 1958: Bonfiglio and Voke 1968; Boettcher, Bonfiglio and Smith 1970; Wagner and Zeiler 1981; Sugioka et al 1982; Saito, Ohzono and Ono 1988; Beltran et al 1990; Cohen. Bonfiglio and Campbell 1990; Chan et al 1991: Santore 1991).

A number of methods have been used to estimate or measure the size of the lesions, and have been adapted for specific needs. For example, selection for intertrochanteric osteotomy depends on whether the osteotomy can shift the necrotic segment out of the region of maximum weightbearing and replace it with normal bone and cartilage. Kerboul et al (1974) described a technique of measuring AP and lateral radiographs for this purpose and their observations were confirmed by Wagner and Zeiler (1981). A similar method which used only the lateral radiograph was shown to be useful in predicting results after an anterior rotational osteotomy by Sugioka et al (1982).

Table III. Progression of AVN after decompression and grafting in 73 stage-I and stage-II hips

\begin{tabular}{llll}
\hline $\begin{array}{l}\text { Size of } \\
\text { lesion }\end{array}$ & $\begin{array}{l}\text { Radiological } \\
\text { progression on } \\
\text { a 20-point scale }\end{array}$ & $\begin{array}{l}\text { Change in } \\
\text { Harris } \\
\text { hip score }\end{array}$ & $\begin{array}{l}\text { THR required } \\
\text { (per cent) }\end{array}$ \\
\hline A $(<15 \%)$ & 1.1 & +10.6 & 7 \\
B (15\% to 30\%) & 4.5 & +3.3 & $3 l$ \\
C (> 30\%) & 4.3 & -3.6 & 3.3 \\
$\begin{array}{l}\text { Significance } \\
\text { of difference }\end{array}$ & $\mathrm{p}=0.05$ & $\mathrm{p}=0.098$ & $\mathrm{p}=0.048$ \\
\hline
\end{tabular}


Other Japanese authors have noted that both the size and location of lesions helped to forecast the outcome; the best results were associated with small medial lesions which did not involve the weight-bearing portion of the femoral head (Inoue and Ono 1979; Ono et al 1986; Saito et al 1988; Ohzono et al 1991).

The clear correlation between outcome and size of the necrotic segment means that any effective method of evaluation and staging must include the measurement of size. Our system combines both distinction between stages and measurement of the extent of involvement within each stage. Research on AVN and its treatment will benefit considerably if a uniform and quantitative method for staging and evaluation can be adopted. We hope that the system which we describe will help to improve the treatment of patients who suffer from this very frustrating condition.

No benefits in any form have been received or will be received from a commercial party related directly or indirectly to the subject of this article.

\section{REFERENCES}

Beltran J, Knight CT, Zuelzer WA, et al. Core decompression for avascular necrosis of the femoral head: correlation between long-term results and preoperative MR staging. Radiology 1990:175:533-6.

Boettcher WG, Bonfiglio M, Smith K. Non-traumatic necrosis of the femoral head. Part II: experiences in treatment. J Bone Joint Surg [Am] 1970;52-A:322-9.

Bonfiglio M, Bardenstein MB. Treatment by bone-grafting of aseptic necrosis of the femoral head and non-union of the femoral neck (Phemister technique). J Bone Joint Surg /Am/ 1958;40-A:1329-46.

Bonfiglio M, Voke EM. Aseptic necrosis of the femoral head and nonunion of the femoral neck: effect of treatment by drilling and bonegrafting (Phemister technique). J Bone Joint Surg [Am] 1968:50-A: 48-66.

Cohen J, Bonfiglio M, Campbell CJ. Aseptic necrosis. In: Orthopedic pathophysiology in diagnosis and treatment. New York, etc: Churchill Livingstone, 1990:245-332.

Chan TW, Dalinka MK, Steinberg ME, Kressel HY. MRI appearance of femoral head osteonecrosis following core decompression and bone grafting. Skeletal Radiol 1991;20:103-7.

Ficat RP. Idiopathic bone necrosis of the femoral head: early diagnosis and treatment. J Bone Joint Surg [Br] 1985;67-B:3-9.

Ficat RP, Arlet J. Necrosis of the femoral head. In: Hungerford DS, ed. Ischemia and necrosis of bone. Baltimore, etc: Williams \& Wilkins, 1980:171-82.
Hungerford DS. Bone marrow pressure, venography and core decompression in ischemic necrosis of the femoral head. In: The hip: proceedings of the seventh open scientific meeting of The Hip Society: St Louis: CV Mosby, 1979:218-37.

Inoue A, Ono K. A histological study of idiopathic avascular necrosis of the head of the femur. J Bone Joint Surg [Br] 1979:61-B:138-43.

Kerboul M, Thomine J, Postel M, Merle d'Aubigné R. The conservative surgical treatment of idiopathic aseptic necrosis of the femoral head. J Bone Joint Surg [Br] 1974;56-B:291- 6.

Marcus ND, Enneking WF, Massam RA. The silent hip in idiopathic aseptic necrosis: treatment by bone grafting. J Bone Joint Surg [Am] 1973:55-A:1351-66.

Mitchell MD, Kundel HL, Steinberg ME, et al. Avascular necrosis of the hip: comparison of MR, CT and scintigraphy. $A J R$ 1986:147:67-71.

Mitchell DG, Rao VM, Dalinka MK, et al. Femoral head avascular necrosis: correlation of MR imaging, radiographic staging, radionuclide imaging, and clinical findings. Radiology 1987;162:709-15.

Mitchell DG, Steinberg ME, Dalinka MK, et al. Magnetic resonance imaging of the ischemic hip: alterations within the osteonecrotic, viable, and reactive zones. Clin Orthop 1989;244:60-77.

Ohzono K, Saito M, Takaoka K, et al. Natural history of nontraumatic avascular necrosis of the femoral head. J Bone Joint Surg $[\mathrm{Br}]$ 1991:73-B:68-72.

Ono K, et al. Annual report of Japanese investigation committee for avascular necrosis of the femoral head. (In Japanese) 1986:331-6.

Saito S, Ohzono K, Ono K. Joint-preserving operations for idiopathic avascular necrosis of the femoral head: results of core decompression. grafting. and osteotomy. J Bome Joint Surg /Br/ 1988;70-B:78-84.

Santore RF. Intertrochanteric osteotomy for osteonecrosis. Seminars in Arthroplasty 1991;2:208-13.

Steinberg ME. Early diagnosis of avascular necrosis of the femoral head. AAOS Instructional Course Lectures 1988:XXXVII:51-7.

Steinberg ME, Hayken GD, Steinberg DR. A new method for evaluation and staging of avascular necrosis of the femoral head. In: Arlet J, Ficat RP, Hungerford DS, eds. Bone circulation. Baltimore, etc: Williams \& Wilkins, 1984:398-403.

Steinberg ME, Corces A, Fallon M. Acetabular involvement in avascular necrosis (AVN) of the femoral head. Orthop Trans 1989;13:518.

Steinberg ME, Thickman D, Chen HH, et al. Early diagnosis of avascular necrosis by magnetic resonance imaging. In: Arlet J, Mazières B, eds. Bone circulation and bone necrosis. Berlin, etc: Springer-Verlag, 1990:281-5.

Steinberg ME, Bands RE, Parry S, et al. Does lesion size affect outcome in avascular necrosis. Orthop Trans 1992-1993:16:706-7.

Sugioka Y, Katsuki I, Hotokebuchi T. Transtrochanteric rotational osteotomy of the femoral head for the treatment of osteonecrosis: follow-up statistics. Clin Orthop 1982:169:115-26

Wagner H, Zeiler G. Idiopathic necrosis of the femoral head: results of intertrochanteric osteotomy and joint resurfacing. In: Weil UH, ed Segmental idiopathic necrosis of the femoral head. Progress in orthopaedic surgery, Vol. 5. Berlin, etc: Springer-Verlag, 1981:87-116. 